Scientia Agricola

http://dx.doi.org/10.1590/0103-9016-2014-0343

\title{
Dispersal capacity of fruit fly parasitoid Diachasmimorpha longicaudata (Hymenoptera: Braconidae) in irrigated coffee plantations
}

\author{
Maria Gisely Camargos ${ }^{1}$, Clarice Diniz Alvarenga ${ }^{*}$, Teresinha Augusta Giustolin ${ }^{1}$, Beatriz Aguiar Jordão Paranhos², Patrícia \\ Cristina do Carmo Oliveira ${ }^{1}$, Marcelo Mendes Rabelo ${ }^{1}$
}

\author{
${ }^{1}$ State University of Montes Claros - Dept. of Agricultural \\ Sciences, R. Reinaldo Viana, 2630 - 39440-000 - Janaúba, \\ $M G$ - Brazil. \\ 2EMBRAPA Semiarid - Entomology Lab., Rod. BR-428, km \\ 152 - 56302-970 - Petrolina, PE - Brazil. \\ *Corresponding author <clarice.corsato@unimontes.br>
}

Edited by: Richard V. Glatz

Received October 01, 2014

Accepted December 14, 2015
ABSTRACT: Diachasmimorpha longicaudata is an Old World parasitoid of tephritid fruit flies that was widely introduced in the Americas to control pest species such as the Mediterranean fruit fly Ceratitis capitata. Augmentative releases in irrigated coffee plantations in semiarid regions of Brazil are under consideration and dispersal capacity of $D$. longicaudata in this habitat are important to develop release strategies. Approximately 2,000 individuals of $D$. Iongicaudata (5 to 7 days old) were released in the center of a fruiting coffee plantation every two weeks from Dec. 2009 to Apr. 2010. Dispersal from the central release point was monitored to the north, south, east, west, northeast, northwest, southeast and southwest at 11 distances, beginning at $4.6 \mathrm{~m}$ and ending at $90 \mathrm{~m}$ from the release point. At each point, a parasitism unit (approximately 120 larvae of $C$. capitata in the $3^{\text {rd }}$ instar wrapped in voile fabric) and 10 coffee beans were collected. The average dispersion distance and dispersion area were estimated by the model proposed by Dobzhansky and Wright (1943). The average dispersion distances were $27.06 \mathrm{~m}$ (as estimated by fruit collection) and $33.11 \mathrm{~m}$ (as estimated by oviposition traps). The average dispersion areas were $1,315.25 \mathrm{~m}^{2}$ and $1,752.45 \mathrm{~m}^{2}$ originating from the collection of beans and parasitism units, respectively. Cohorts of 2,000 adult $D$. longicaudata released at six points ha-1 are estimated to result in sufficient colonization to exert significant control of Ceratitis capitata. Keywords: Ceratitis capitata, parasitism, average distance of dispersion area, dispersion area

\section{Introduction}

The success of augmentative biological control depends upon the ability of released parasitoids to disperse and locate adult foods, shelter, and hosts (Paranhos et al., 2007). The term dispersion can be used to designate the diffusion or migration of individuals of a population or it may be related to the spatial distribution of individuals in a population at a given time (Okubo, 1980; Kareiva, 1986; Turchin, 1989). Movement within an environment can be influenced by plant architecture, height, spacing and phenological state (Gontijo et al., 2010). Thus, the nature of the vegetative habitat and its effect on natural enemy dispersal must be considered when determining the numbers of adults to be released and how and when these releases are performed (Zachrisson and Parra, 1998).

The Asian Diachasmimorpha longicaudata (Ashmead) is the most widely introduced Opiinae tephritid fruit fly parasitoid and is arguably the most studied and argumentatively released parasitoid of fruit flies for the control of Ceratitis capitata (Paranhos et al., 2008) and Anastrepha spp. flies (Montoya et al., 2000; Sivinski et al., 1996). D. longicaudata is a larval-prepupal parasitoid that performs best when provided hosts in late $2^{\text {nd }}$ and early $3^{\text {rd }}$ instars. It is relatively simple to mass rear and it forages on fruit on trees and on the ground (Purcell et al., 1994; Sivinski et al., 1998).

Nevertheless, only little information is available on the behavior of $D$. longicaudata in Brazilian agricultural habitats. Therefore, a successful method for local augmentative release, e.g., density of release points and number of parasitoids to be released, is yet to be formulated. Dispersal, survival and parasitism studies are particularly important when they occur in environments considered to have marginal suitability for $D$. longicaudata (Paranhos et al., 2007). One such environment is coffee (Coffea arabica) plantations in the hot and dry regions of the northern Minas Gerais, Brazil, which is infested with the Mediterranean fruit fly Ceratitis capitata. Coffee is a habitat of concern as it serves as a reservoir for fruit fly populations (Camargos et al., 2015).

In the present study, we tested dispersal by measuring $D$. longicaudata movement from a central release point in a coffee plantation. We estimated the dispersal capacity, seasonal changes in parasitism rates and ultimately recommend the best procedures for augmentative releases.

\section{Materials and Methods}

Field experiments were carried out during five months (Dec 2009 to Apr 2010) in Jaíba, Minas Gerais,

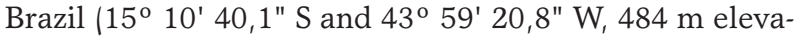
tion), in two hectares with irrigated plantation of Catuaî Vermelho coffee variety.Throughout the study period, no pesticides were sprayed for fruit fly control and no individuals of $D$. longicaudata were released prior to the experiments. The local climate is considered tropical semiarid (Koppen classification) and is characterized by dry winters. The average temperature in the region is 24 ${ }^{\circ} \mathrm{C}$, with a mean elevation of $500 \mathrm{~m}$ and an average annual precipitation of $871 \mathrm{~mm}$ (Silva et al., 2012). 
The $D$. longicaudata used in the experiments were reared using $3^{\text {rd }}$ stage larvae of $C$. capitata as hosts. Adults parasitoids were kept in wooden framed cages $(30 \times 30 \times 40 \mathrm{~cm})$, covered with organdy mesh, containing approximately 1,000 individuals (sex ratio 1:3, males: females). The adults were provided with water and artificial food source based on honey and water.

Starting from the center of the experimental area, points in the coffee plantation were marked, radiating in the four cardinal directions (north, south, east, and west) and four collateral directions (northeast, northwest, southeast, and southwest). The points were chosen according to plants distribution in the coffee plantation and dictated by spacing between the rows and area. Eleven circles were marked, with radiuses of 4.6 , $10,18,25,33,41,49,56,64,72$, and $90 \mathrm{~m}$, and one point in each direction or eight points per circle, except for the first and last circles, which comprised only four points, totaling 80 points (Figure 1).

Approximately 2,000 parasitoids (1:3, males:females) were released in the center of the marked area at two-week intervals throughout the coffee fruiting period of Dec. 2009 to Apr. 2010, totaling eight releases. The parasitoids were five to seven days old and within their period of maximum fecundity (López et al., 2009).

In order to estimate the dispersal of $D$. longicaudata in the field, a parasitism unit was placed at each marked sampling-point. These parasitism units consisted of about 120 larvae of $C$. capitata in the $3^{\text {rd }}$ instar and artificial food source wrapped in voile fabric, with the dimensions simulating the volume of an infested fruit (Figure 2). The use of traps such as these parasitism units containing larva plus diet attracts parasitoids, reducing the dilution effect of the area, that is, it facilitates to reach the farthest points in the outer circles of the dispersal area (Mills et al., 2006).

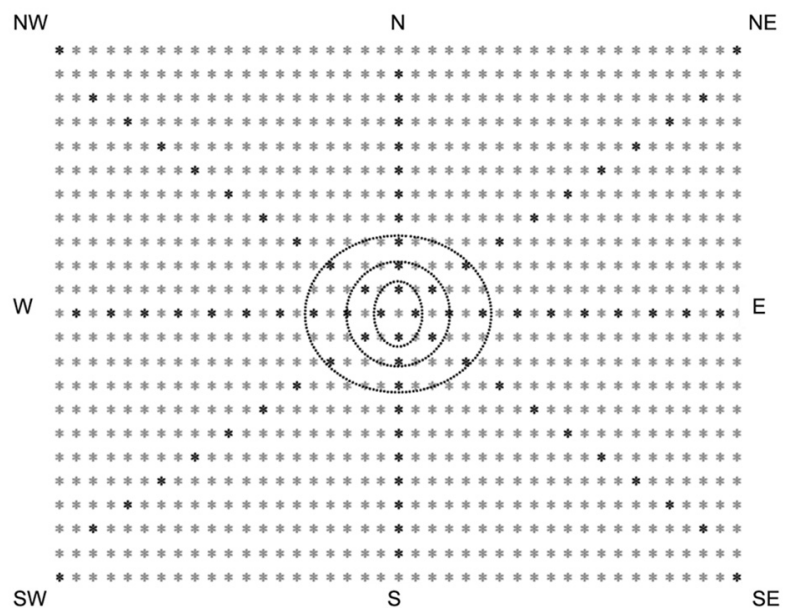

Figure 1 - Distribution design of assessment points of dispersion capacity of Diachasmimorpha longicaudata in a coffee plantation. From 11 circumferences, only three were represented for illustration purposes.
The parasitism units were hung on coffee trees at a height between 1.0 and $1.3 \mathrm{~m}$ from ground level. Parasitism units were placed at each sample point, totaling eight units per circle, with four parasitism units in the first and last circle, so that each cardinal and collateral direction had ten parasitism units (Figure 1). The parasitism units were deployed for $24 \mathrm{~h}$ each, before they were replaced with a new parasitism unit that remained deployed for another $24 \mathrm{~h}$. Thus, samples were taken $24 \mathrm{~h}$ and $48 \mathrm{~h}$ after parasitoid release to ensure that the parasitism rate was not cumulative. The larvae removed from the units were put in $200 \mathrm{~mL}$ plastic cups containing a moist vermiculite layer and covered with voile fabric in order to pupate. Containers were identified by date, location (direction and point) and stored in the laboratory, where they remained under temperature controlled conditions $\left(27 \pm 1^{\circ} \mathrm{C}\right)$. After emergence, adult flies and parasitoids were preserved in $70 \%$ ethanol and held in collection at Janaúba, MG, Brazil.

Ten mature coffee fruits were randomly collected from the trees canopy at the previously mentioned sample sites. Four collections (Mar 3 and 24, 2010 and Apr 7 and 21, 2010) were carried out in all 80 sampling points $24 \mathrm{~h}$ after the parasitoid release. The fruits were put in $200 \mathrm{~mL}$ plastic cups containing moist vermiculite, covered with voile fabric and kept in the laboratory at a controlled temperature $27 \pm 1{ }^{\circ} \mathrm{C}$. After ten days, pupae from the vermiculite were screened and fruit pulps were examined carefully. The larvae and the puparia were counted and transferred to glass containers containing vermiculite and covered with voile fabric. Adult insects were preserved in $70 \%$ ethanol and kept in the authors' collection until identification.

Fruit infestation level (I) was calculated as the mean number of puparia per fruit. Parasitism rate $(\% \mathrm{P})$ was calculated for each sample in each collection (both for parasitism units and for fruit collections).

$\% \mathrm{P}=$ [number of adults of parasitoid $D$. longicaudata emerged / total number of adults (D. longicaudata and fruit flies) emerged] $\times 100$

A relationship between dispersal (distance from the center to the marked points) and parasitism (24 and $48 \mathrm{~h}$ after the release) was calculated through the Pearson correlation $(\mathrm{r})$ and linear regression analyses (SASStatistical Analysis System, version 9).

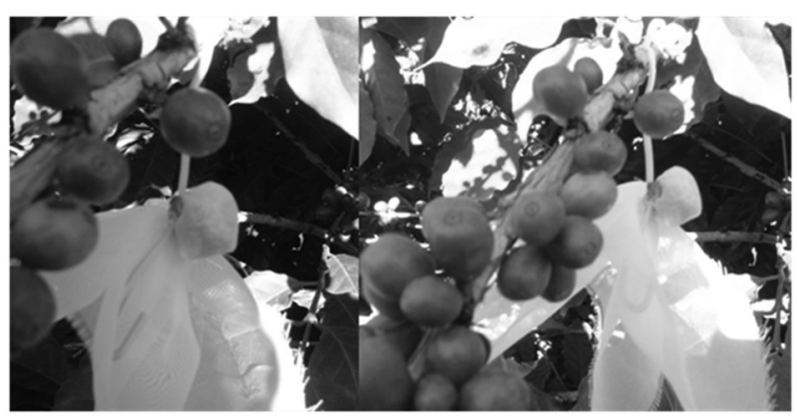

Figure 2 - Parasitism unit in coffee plant. 
The average distance of dispersion (DM) and the dispersal area $\left(\mathrm{S}^{2}\right)$ of the parasitoid in the plantation, for each collection (evaluation), were estimated by the model proposed by Dobzhansky and Wright (1943) described below:

$\mathrm{S}^{2}=\left[\Sigma\left(\mathrm{r}^{3} \times \mathrm{i} / \mathrm{a}\right) / \Sigma(\mathrm{r} \times \mathrm{i} / \mathrm{a})+\mathrm{C} / 2 \pi\right] ; \mathrm{DM}=\left[\Sigma\left(\mathrm{r}^{2} \times \mathrm{i} / \mathrm{a}\right) /\right.$ $\Sigma(\mathrm{r} \times \mathrm{i})+\mathrm{C} / 2 \pi)]$

where: $\mathrm{S}^{2}\left(\mathrm{~m}^{2}\right)=$ dispersion area $\left(\mathrm{m}^{2}\right)$ during the experimental period; $\mathrm{DM}(\mathrm{m})=$ average dispersion distance $(\mathrm{m})$ of parasitoids during the experimental period; $\mathrm{r}=$ distance $(\mathrm{m})$ from the center to the traps (parasitism units or fruit collection points); $a=$ the number of traps per circle (four for the first and last circles and eight for the other circles, at the distances (radius) studied); $\mathrm{C}=$ average parasitoids recaptured in the central circle; $\mathrm{i}=$ parasitism rate (parasitism units and fruits) in each circle.

In order to relate the dispersal area $\left(\mathrm{S}^{2}\right)$ and the average dispersion distance (DM) of the parasitoids to local weather factors (temperature, precipitation, wind speed and relative air humidity), the data were analyzed by the Pearson correlation $(\mathrm{r})$ and linear regression. The monthly average values of climate data were obtained in a Climatological Station in Jaíba, Minas Gerais State, Brazil, about $5 \mathrm{Km}$ from the experimental area.

\section{Results}

During the trial period, the average monthly precipitation was $13.9 \mathrm{~mm}$, the average temperature was $25.5^{\circ} \mathrm{C}$ and the mean relative humidity was $71 \%$.

In previous samples of fruit collected between March and June 2009, before the releases of D. longicaudata, the average infestation rate of fruit flies in coffee beans was 194.2 pupae $\mathrm{kg}^{-1}$ and 0.2 pupae per fruit. We registered 615 adults emerged from the coffee fruit 1614 Ceratitis capitata and only one parasitoid Doryctobracon areolatus (Szépligeti) (Hymenoptera: Braconidae)). No individuals of $D$. longicaudata were collected during these preliminary surveys (Camargos et al., 2015). Therefore, we assume that all individuals of $D$. longicaudata recovered in our study either from fruit samples or in our parasitism units originated from the augmentative releases performed as part of this experiment.

No native parasitoid species were recorded emerging from the fruit samples or from the parasitism units after the experimental releases. Twenty adults of $D$. longicaudata emerged from the beans collected $24 \mathrm{~h}$ after the releases and 679 fruit flies, being 677 C. capitata 1356 females and 321 males) and two males of Anastrepha sp. Parasitoids were recovered from coffee beans after the four releases. The average distance estimated in which $D$. longicaudata parasitized on $C$. capitata in the fruit was $27.06 \mathrm{~m}$ from the release site and the average area occupied by the parasitoid following release of 2,000 individuals was estimated at $1,315.25 \mathrm{~m}^{2}$ (Table 1 ).
Table 1 - Infestation of fruit flies (pupae/fruit), parasitism (\%), average distance (DM) and dispersal area $\left(\mathrm{S}^{2}\right)$ of parasitoid $D$. longicaudata in fruit samples (collected $24 \mathrm{~h}$ after releases).

\begin{tabular}{lccrrr}
\hline Release date & Infestation & Parasitism & \multicolumn{1}{c}{ DM } & \multicolumn{1}{c}{$\mathrm{S}^{2}$} \\
\hline & & $\%$ & & & \\
\cline { 4 - 5 } $3 / 2 / 2010$ & 0.4052 & 4.86 & 40.23 & $2,132.9$ \\
$3 / 23 / 2010$ & 0.0012 & 5.12 & 13.81 & 264.78 \\
$4 / 6 / 2010$ & 0.0187 & 1.20 & 4.44 & 20.46 \\
$4 / 20 / 2010$ & 0.0175 & 1.27 & 49.78 & $2,842.86$ \\
\hline
\end{tabular}

The parasitism units were collected $24 \mathrm{~h}$ and $48 \mathrm{~h}$ after the release. The parasitism rate of $D$. longicaudata varied among releases and distances from the release point (Table 2). The highest parasitism rate $(45 \%)$ occurred in the second radius $10 \mathrm{~m}$ far from the center release point) and the lowest $(0 \%)$ was obtained in seven out of 16 evaluations in different points on different dates, however, there was no pattern.

Based on the model of Dobzhansky and Wright (1943) and the larvae obtained from the array of parasitism units, $D$. longicaudata infested larvae occurred up to a maximum distance of $76.12 \mathrm{~m}$ from the center release point and occupied a maximum dispersion area of $6,368.57 \mathrm{~m}^{2}$ after only $24 \mathrm{~h}$ from the release time (Table $3)$. The highest average parasitism rate (19\%) occurred after $48 \mathrm{~h}$. The average distance of parasitoid dispersal was $35.78 \mathrm{~m}$ after $24 \mathrm{~h}$ and average dispersion areas were 2217.55 and $1287.35 \mathrm{~m}^{2}$ after $24 \mathrm{~h}$ and $48 \mathrm{~h}$, respectively (Table 3). Parasitism was negatively related to distance $(\mathrm{r}=0.80,24 \mathrm{~h}$ after release; $\mathrm{r}=0.90,48 \mathrm{~h}$ after release) from the release-site (Table 4), although some parasitism occurred at the farthest sampling distance of $90 \mathrm{~m}$ (Figures $3 \mathrm{~A}$ and $3 \mathrm{~B}$ ). No significant correlations were observed between the average distance of dispersal estimated DM $(\mathrm{m})$ and the estimated colonized area $\mathrm{S}^{2}$ $\left(\mathrm{m}^{2}\right)$ or any abiotic factors (precipitation, temperature, wind speed and relative air humidity) (Table 5).

\section{Discussion}

We did not recover any native parasitoid during this study. Although we obtained one individual of Doryctobracon areolatus, parasitism of flies found on the coffee beans was close to zero before the release of $D$. longicaudata (Camargos et al., 2015). A similar condition was observed in domestic and commercial orchards in the same region (Alvarenga et al., 2009). However, coffee cultivation in the region is a relatively recent development (the first planting report is from the year 2001) and the first study on natural predators and parasites associated with coffeepest fly species was carried out by Camargos et al. (2015).

Twenty four hours after release, D. longicaudata parasitized medfly larvae in coffee beans at an average distance of up to $49.78 \mathrm{~m}$ from the release points and occupied an area of up to $2,842.86 \mathrm{~m}^{2}$ (Table 1). This is in contrast to a previous release of $D$. longicaudata in a commercial guava orchard where, after $24 \mathrm{~h}$, parasitoids 
Table 2 - Parasitism rate of $D$. longicaudata in C. capitata larvae placed in parasitism units at different distances (radius) from release points (for 24 (a) and 48 (b) hours after releases).

\begin{tabular}{|c|c|c|c|c|c|c|c|c|c|c|c|c|c|}
\hline \multirow{2}{*}{ Release date } & & \multicolumn{11}{|c|}{ Distance from release $(\mathrm{m})$} & \multirow[b]{2}{*}{ Average } \\
\hline & & 4.6 & 10 & 18 & 25 & 33 & 41 & 49 & 56 & 64 & 72 & 90 & \\
\hline \multirow{3}{*}{$12 / 22 / 2009$} & & & & & & & & & & & & & $\%$ \\
\hline & a & 0.83 & 17.18 & 12.29 & 16.66 & 5.20 & 5.62 & 8.12 & 2.70 & 5.10 & 4.16 & 0.83 & 7.15 \\
\hline & $b$ & 18.95 & 44.79 & 27.39 & 20.20 & 23.33 & 21.97 & 21.14 & 9.58 & 9.37 & 4.16 & 0.83 & 18.33 \\
\hline \multirow{2}{*}{ 01/05/2010 } & a & 6.87 & 10.0 & 7.08 & 5.10 & 2.70 & 5.41 & 2.60 & 2.91 & 1.77 & 1.25 & 2.50 & 4.38 \\
\hline & $\mathrm{b}$ & 6.66 & 8.95 & 6.97 & 8.33 & 4.58 & 3.02 & 2.60 & 1.56 & 0.10 & 1.35 & 0.20 & 4.02 \\
\hline \multirow{2}{*}{ 01/20/2010 } & a & 0 & 2.29 & 0.72 & 0.31 & 0 & 0.62 & 0 & 0.31 & 0 & 1.04 & 1.66 & 0.63 \\
\hline & $b$ & 13.75 & 16.66 & 3.54 & 4.47 & 1.97 & 1.14 & 1.45 & 1.04 & 0.72 & 1.97 & 1.45 & 4.37 \\
\hline \multirow{2}{*}{ 02/02/2010 } & $\mathrm{a}$ & 0 & 0.10 & 0 & 0.10 & 0 & 0 & 0 & 0 & 0 & 0 & 0 & 0.01 \\
\hline & $\mathrm{b}$ & 0 & 0.93 & 0.20 & 0.52 & 0.52 & 0 & 0 & 0 & 0 & 0 & 0 & 0.19 \\
\hline \multirow{2}{*}{ 03/02/2010 } & a & 20.41 & 37.18 & 21.45 & 24.06 & 16.25 & 9.47 & 20.00 & 10.41 & 10.10 & 8.64 & 2.50 & 16.40 \\
\hline & $b$ & 12.5 & 9.58 & 9.06 & 1.77 & 0.93 & 2.70 & 0.93 & 0.31 & 0.10 & 1.56 & 0.20 & 3.60 \\
\hline \multirow{2}{*}{ 03/23/2010 } & a & 3.75 & 5.52 & 3.43 & 2.91 & 0.10 & 1.56 & 0 & 0 & 0 & 0 & 0 & 1.57 \\
\hline & $\mathrm{b}$ & 3.95 & 2.70 & 2.70 & 1.87 & 0.72 & 0 & 0 & 0 & 0 & 0 & 0 & 1.08 \\
\hline \multirow{2}{*}{ 04/06/2010 } & a & 12.70 & 12.29 & 0.83 & 1.14 & 0.52 & 0.10 & 1.14 & 0 & 0 & 0.10 & 1.87 & 2.79 \\
\hline & $\mathrm{b}$ & 0.41 & 0.52 & 0.10 & 0 & 0 & 0.20 & 0 & 0 & 0 & 0.10 & 0 & 0.12 \\
\hline \multirow{2}{*}{ 04/20/2010 } & $\mathrm{a}$ & 1.45 & 5.31 & 0.41 & 0.83 & 0.10 & 0.72 & 0.10 & 0.10 & 0.14 & 0 & 0 & 0.83 \\
\hline & $b$ & 2.08 & 1.35 & 0.72 & 0 & 0 & 0 & 0 & 0 & 0 & 0 & 0 & 0.37 \\
\hline \multirow{2}{*}{$\%$ Average } & a & 5.75 & 11.23 & 5.77 & 6.38 & 3.10 & 2.93 & 3.99 & 2.05 & 2.13 & 1.89 & 1.17 & \\
\hline & $\mathrm{b}$ & 7.28 & 10.68 & 6.33 & 4.64 & 4.0 & 3.62 & 3.26 & 1.56 & 1.28 & 1.14 & 0.33 & \\
\hline
\end{tabular}
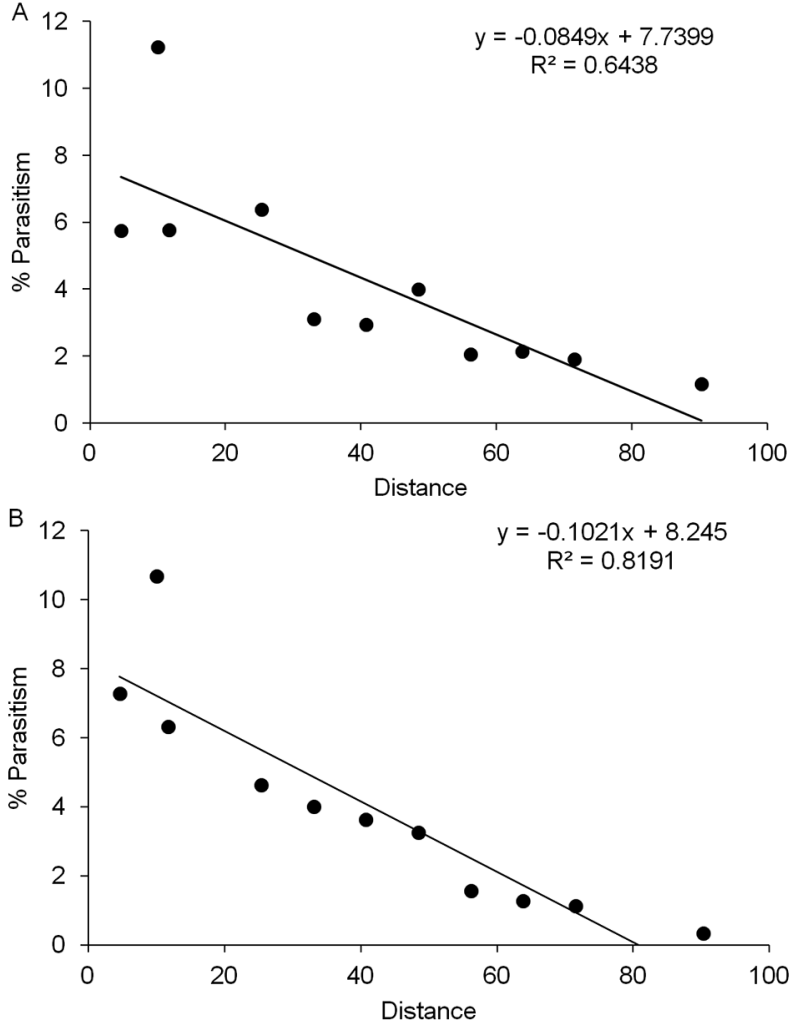

Figure 3 - Average parasitism rate (non-cumulative parasitism rate) by $D$. longicaudata in $C$. capitata larvae placed in parasitism units located in different distances (radius) from the release point in an irrigated coffee plantation, Brazil. A) Average parasitism rate after $24 \mathrm{~h}$ of parasitoids release. B) Average parasitism rate after $48 \mathrm{~h}$ of parasitoids release. had attacked larvae at distances of only $20 \mathrm{~m}$ (Leal et al., 2008). In part, this difference may be due to the larger sample size of coffee fruits and to certain characteristics of the host plant, e.g., volatility of aromatic compounds. For example, different levels of parasitism can be obtained in the same host in different cultures and, in some cases, parasitoids are more specific in relation to the habitat than to hosts (Ables et al., 1980; Andow and Prokrym, 1991).

In general, parasitism was lower than typically found in field studies. $D$. longicaudata prefers to parasitize host larvae infesting fruit on the ground (Haramoto and Bess, 1970; Sivinski et al., 1997). Silva et al. (2007) observed that $D$. longicaudata shows preference to visit rotten guavas than ripe ones. Segura et al. (2012) showed that oranges previously infested with $C$. capitata, without the presence of larva, were more attractive to females of $D$. longicaudata than non-infested fruits. The authors also concluded that rotten fruits, even when not infested with fruit flies, attracted female parasitoids more than ripe fruits. This suggests that the females use volatile compounds indirectly associated with $C$. capitata larvae. When infested, fruits become rotten more quickly than non-infested ones and, according to Segura et al. (2012), volatiles released by rotten fruits would suggest a higher infestation probability than the ripe fruit itself. If coffee beans are collected at a more advanced maturation stage, i.e., when they have already fallen to the ground, this could result in a larger number of parasitoids recovered as the compounds released by rotten fruits could guide females to the location from further afield, with higher probability of finding the host in infested fruits. In this study, coffee beans were collected only from the canopy of trees after releases. 
Table 3 - Average parasitism rate after 24 and 48 hours of releases, average distance $(\mathrm{DM})$ and dispersal area $\left(\mathrm{S}^{2}\right)$ reached by parasitoid $D$. longicaudata estimated during the study period, using parasitism units containing $C$. capitata larvae in an irrigated coffee plantation, in Jaíba - Minas Gerais. (Dec. 2009 through Apr. 2010).

\begin{tabular}{|c|c|c|c|c|}
\hline \multirow{2}{*}{\multicolumn{2}{|c|}{ Release date }} & Average percentage & DM & $S^{2}$ \\
\hline & & $\%$ & $\mathrm{~m}$ & $\mathrm{~m}^{2}$ \\
\hline \multicolumn{2}{|c|}{$12 / 23 / 09$ (24 h) } & 7.79 & 45.74 & $2,517.59$ \\
\hline \multicolumn{2}{|c|}{$12 / 24 / 09$ (48 h) } & 19.18 & 39.09 & $1,962.64$ \\
\hline \multicolumn{2}{|c|}{ 1/6/10 (24 h) } & 4.35 & 17.93 & $1,218.82$ \\
\hline \multicolumn{2}{|c|}{ 1/7/10 (48 h) } & 4.09 & 33.24 & $1,599.35$ \\
\hline \multicolumn{2}{|c|}{$1 / 21 / 10$ (24 h) } & 0.61 & 76.12 & $6,368.57$ \\
\hline \multicolumn{2}{|c|}{$1 / 22 / 10$ (48 h) } & 4.06 & 39.25 & $2,673.54$ \\
\hline \multicolumn{2}{|c|}{ 2/3/10 (24 h) } & 0.02 & 21.01 & 489.63 \\
\hline \multicolumn{2}{|c|}{ 2/4/10 (48 h) } & 0.21 & 24.48 & 677.98 \\
\hline \multicolumn{2}{|c|}{$3 / 3 / 10$ (24 h) } & 16.90 & 43.99 & $2,539.45$ \\
\hline \multicolumn{2}{|c|}{ 3/4/10 (48 h) } & 3.00 & 26.78 & $1,412.37$ \\
\hline \multicolumn{2}{|c|}{$3 / 24 / 10$ (24 h) } & 1.54 & 18.27 & 523.01 \\
\hline \multicolumn{2}{|c|}{$3 / 25 / 10$ (48 h) } & 1.00 & 13.68 & 313.45 \\
\hline \multicolumn{2}{|c|}{ 4/7/10 (24 h) } & 2.34 & 41.46 & $3,325.95$ \\
\hline \multicolumn{2}{|c|}{ 4/8/10 (48 h) } & 0.11 & 29.19 & $1,584.99$ \\
\hline \multicolumn{2}{|c|}{ 4/21/10 (24 h) } & 0.94 & 21.79 & 757.37 \\
\hline \multicolumn{2}{|c|}{ 4/22/10 (48 h) } & 0.31 & 5.82 & 74.51 \\
\hline \multirow{2}{*}{ Average } & $24 \mathrm{~h}$ & - & 35.78 & $2,217.55$ \\
\hline & $48 \mathrm{~h}$ & & 26.44 & $1,287.35$ \\
\hline
\end{tabular}

Table 4 - Pearson correlation $(r)$ between the distance $(m)$ where parasitism units were installed and the parasitism rate $24 \mathrm{~h}$ and $48 \mathrm{~h}$ after release of $D$. longicaudata in irrigated coffee plantation.

\begin{tabular}{lcc}
\hline Interactions & $\begin{array}{c}\text { Pearson correlation } \\
\text { coefficient }(r)\end{array}$ & Correlation \\
\hline Parasitism $\times$ distance $(24 \mathrm{~h})$ & 0.80 & Strong \\
Parasitism $\times$ distance $(48 \mathrm{~h})$ & 0.90 & Strong \\
\hline
\end{tabular}

Values 0.70 upward or downward indicate a strong correlation. From 0.30 to 0.7 positive or negative indicate mild correlation and 0 to 0.30 means poor correlation.

Table 5 - Pearson correlation $(r)$ between each of the abiotic factors (relative humidity, temperature, wind speed and precipitation) and the variables average distance of dispersion DM $(\mathrm{m})$ or dispersal area $S^{2}\left(\mathrm{~m}^{2}\right)$ of $D$. longicaudata after release in an irrigated coffee plantation.

\begin{tabular}{lcc}
\hline Interactions & Pearson correlation coefficient $(r)$ & Correlation \\
\hline Relative humidity $\times \mathrm{DM}$ & 0.13 & Poor \\
Relative humidity $\times \mathrm{S}^{2}$ & 0.16 & Poor \\
Temperature $\times \mathrm{DM}$ & 0.17 & Poor \\
Temperature $\times \mathrm{S}^{2}$ & -0.07 & Poor \\
Wind speed $\times \mathrm{DM}$ & -0.35 & Mild \\
Wind speed $\times \mathrm{S}^{2}$ & -0.36 & Mild \\
Precipitation $\times \mathrm{DM}$ & 0.35 & Mild \\
Precipitation $\times \mathrm{S}^{2}$ & 0.15 & Poor \\
\hline
\end{tabular}

Values 0.70 upward or downward indicate a strong correlation. From 0.30 to 0.7 positive or negative indicate mild correlation and 0 to 0.30 means poor correlation.
Removing the fruit from the field during the sampling procedure reduces the period when the larvae are susceptible to attack, resulting in underestimated parasitism (Sivinski et al., 1996). Thus, for D. longicaudata, the most accurate samples are obtained from fallen fruit in which all larvae matured, but none was left to pupate. Our removal of some maturing beans from coffee plants, not the soil, may have led to substantial underestimates of parasitism rates.

Another explanation for the low parasitism rate in fruit following $D$. longicaudata releases was the naturally occurring low infestation level (puparia/fruit) relative to the host density available in the artificial oviposition devices (Table 2). Female parasitoids may forage longer in locations with a larger number of hosts (Alphen and Bernstein, 2008). Therefore, higher host density in parasitism units might have prolonged host searching. Eighty parasitism units installed in the plantation yielded 3,350 D. longicaudata after $24 \mathrm{~h}$ and 3,103 after $48 \mathrm{~h}$. In a previous study in a guava orchard, similar units yielded each an average of 36.6 parasitoids after $24 \mathrm{~h}$ following augmentative releases (Leal et al., 2008). This was comparable to the average of 41.9 and 38.8 parasitoids per parasitism unit in the present study.

Although parasitism was relatively low, both in fruit samples and in the parasitism units, the parasitoid managed to disperse to larger distances than those recorded in guava orchards. It appears that $D$. longicaudata has a high capacity to disperse in coffee plantations under semiarid conditions. Perhaps the habitat structure of coffee plantations presented fewer physical barriers to the parasitoids dispersal than the guava trees did.

In this study, both the parasitism rate and the average dispersal of the parasitoid recaptured in parasitism units were higher in the first $24 \mathrm{~h}$ after release (Table 3). The quick dispersal can increase probability of parasitoids to locate the larvae in infested fruit. However, survival and persistence of the parasitoid in an area depend on a number of factors besides simply the host presence.

The parasitoid dispersal does not seem to be related to climate parameters where it is released (Table 5). Paranhos et al. (2007) correlated the average distance of dispersal (DM) of $D$. longicaudata in citrus orchards, in Piracicaba-SP, Brazil, with climate variables in different seasons of the year. In the summer, climate conditions did not affect the average distance of dispersal and the occupancy area. There was only a small variation of temperature and humidity during the experimental period in the summer. On the other hand, distances reached were greater in the summer than in the winter, probably because of the lower temperature.

The present research showed that both fruit samples and parasitism units might be used to estimate dispersal. The average distances of dispersion and dispersal areas calculated from fruit samples (Table 1) and parasitism units (Table 3) were similar. However, oviposition units are more practical and accurate, since they can be 
homogeneously distributed, they hold equal quantities of hosts and are used regardless of the presence of infested fruits in the area.

Our oviposition-based sampling methods did not reflect the numbers of females dispersing a particular distance, only showing that one or more did so. Females may also have passed sample sites without ovipositing, causing dispersal to be underestimated. The use of attractive traps, perhaps baited with either food and oviposition kairomones or both, (Paranhos et al., 2007) might capture $D$. longicaudata engaged in a broader range of behaviors. However, data reflecting the movements of sexually mature females may be the most important in designing effective strategies for augmentative releases.

The elimination of almost $70 \%$ of fruit flies populations resulting from the augmentative releases of about 940 D. longicaudata parasitoids per hectare in commercial mango orchards, backyard orchards and native vegetation types was demonstrated by Montoya et al. (2000) in Mexico. The present study leads us to recommend, based on the obtained average dispersal area, that cohorts of 2,000 parasitoids be released in six points per hectare. Furthermore, if augmentative releases are used together with other strategies, such as sterile insect technique and cultural control methods, this can result in significant and important synergistic effects on the suppression of the fruit fly population (Sivinski et al., 1996; Montoya et al., 2000). In the future, additional studies incorporating longer post-release sampling periods could estimate $D$. longicaudata persistence in the field and frequently of releases to keep the desired densities of both the pest and the parasitoid species.

\section{Acknowledgments}

We are grateful for the financial support provided by FAPEMIG (Minas Gerais State Foundation for Research Support) (Proceeding No. APQ-00977-09) and for granting BIPDT and BIC scholarships. We also thank CAPES /Coordination for the Improvement of Higher Level Personnel) for granting the Master's scholarship and CNPq (Brazilian National Council for Scientific and Technological Development) for the fellowship awarded to the second author. We thank John Sivinski for the useful review and comments on an earlier version of this manuscript.

\section{References}

Ables, J.R.; McCommas, D.W.; Jones, S.L.; Morrison, R.K. 1980. Effect of cotton plant size, host egg location, and location of parasite release on parasitism by Trichogramma pretiosum. Southwestern Entomologist 5: 261-264.

Alvarenga, C.D.; Matrangolo, C.A.R.; Lopes, G.N.; Silva, M.A.; Lopes, E.N.; Alves, D.A.; Nascimento, A.S.; Zucchi, R.A. 2009. Fruit flies (Diptera: Tephritidae) and their parasitoids in host plants of three counties of north of the state of Minas Gerais. Arquivos do Instituto Biológico 76: 195-204 (in Portuguese, with abstract in English).
Andow, D.A.; Prokrym, D.R. 1991. Releases density, efficiency and disappearance of Trichogramma nubilale for control of European corn borer. Entomophaga 36: 105-113.

Camargos, M.G.; Alvarenga, C.D.; Giustolin, T.A.; Oliveira, P.C.C.; Rabelo, M.M. 2015. Fruit flies (Diptera: Tephritidae) in irrigated coffee plantations in the north of Minas Gerais. Coffee Science 10: 28-37 (in Portuguese, with abstract in English).

Dobzhansky, T.; Wright, S. 1943. Genetics of natural populations $\times$ dispersion rates in Drosophila pseudoobscura. Genetics 28: 304-340.

Gontijo, L.M.; Margolies, D.C.; Nechols, J.R.; Cloyd, R.A. 2010. Plant architecture, prey distribution and predator release strategy interact to affect foraging efficiency of the predatory mite Phytoseiulus persimilis (Acari: Phytoseiidae) on cucumber. Biological Control 53: 136-141.

Haramoto, F.H.; Bess, H.A. 1970. Recent studies on the abundance of the oriental and Mediterranean fruit flies and the status of their parasites. Proceedings of the Hawaiian Entomological Society 20: 551-566.

Kareiva, P. 1986. Trivial movement and foraging by crop colonizers. p. 59-81. In: Kogan, M., ed. Ecological theory and IPM practice. John Wiley, New York, NY, USA.

Leal, R.M.; Aguiar-Menezes, E.L.; Lima Filho, M.; Ribeiro, J.C.R.; Menezes, E.B. 2008. Survival and Dispersal of Diachasmimorpha longicaudata, an Exotic Parasitoid Larvae of Fruit Flies = Capacidade de Sobrevivência e Dispersão de Diachasmimorpha longicaudata, um Parasitoide Exótico de Larva de Moscasdas-Frutas. Embrapa Agrobiologia, Seropédica, RJ, Brazil (in Portuguese).

López, O.P.; Hénaut,Y.; Cancino, J.; Lambin, M.; Cruz-López, L.; Rojas, J.C. 2009. Is host size an indicator of quality in the massreared parasitoid Diachasmimorpha longicaudata (Hymenoptera: Braconidae)? Florida Entomologist 92: 441-449.

Mills, N.J.; Babendreier, D.; Loomans, A.J.M. 2006. Methods for monitoring the dispersal of natural enemies from point source releases associated with augmentative biological control. p. 114-131. In: Bigler, F.; Babendreier, D.; Kuhlmann, U., eds. Environmental impact of invertebrates for biological control of arthropods: methods and risk assessment. CAB International, Wallingford, UK.

Montoya, P.; Liedo, P.; Benrey, B.; Barrera, J.F.; Cancino, J.; Sivinski, J.; Aluja, M. 2000. Biological control of Anastrepha spp. (Diptera: Tephritidae) in mango orchards though augmentative releases of Diachasmimorpha longicaudata (Ashmead) (Hymenoptera: Braconidae). Biological Control 18: 212-224.

Okubo, A. 1980. Diffusion and Ecological Problems: Mathematical Models. Springer, Heidelberg, Germany.

Paranhos, B.A.J.; Mendes, P.C.D.; Papadopoulos, N.T.; Walder, J.M.M. 2007. Dispersion patterns of Diachasmimorpha longicaudata (Hymenoptera: Braconidae) in citrus orchards in southeast Brazil. Biocontrol Science and Technology 17: 375385.

Paranhos, B.A.J.; Costa, M.L.Z.; Ovruski, S.M.; Alves, R.M.; Lummer, L.B.; Walder, J.M.M. 2008. Offspring in response to parental female densities in the fruit fly parasitoid Diachasmimorpha longicaudata (Hymenoptera: Braconidae: Opiinae). Florida Entomology 91: 628-635. 
Purcell, M.F.; Jackson, C.G.; Long, J.P.; Batchelor, M. 1994. Influence of guava ripening on parasitism of the oriental fruit fly, Bactrocera dorsalis (Hendel) (Diptera: Tephritidae), by Diachasmimorpha longicaudata (Ashmead) (Hymenoptera: Braconidae) and other parasitoids. Biological Control 4: 396403.

Segura, D.F.; Viscarret, M.M.; Ovruski, S.M.; Cladera, J.L. 2012. Response of the fruit fly parasitoid Diachasmimorpha longicaudata to host and host-habitat volatile cues. Entomologia Experimentalis et Applicata 143: 164-176.

Silva, J.O.; Espírito-Santo, M.M.; Melo, G.A. 2012. Herbivory on Handroanthus ochraceus (Bignoniaceae) along a successional gradient in a tropical dry forest. Arthropod-Plant Interactions 6: 45-57.

Silva, J.W.P.; Bento, J.M.S.; Zucchi, R.A. 2007. Olfactory response of three parasitoid species (Hymenoptera: Braconidae) to volatiles of guavas infested or not with fruit fly larvae (Diptera:Tephritidae). Biological Control 41: 304-311.

Sivinski, J.M.; Calkins, C.; Baranowski, R.; Harris, D.; Brambila, J.; Diaz, J.; Burns, R.; Holler, T.; Dodson, G. 1996. Supression of a Caribbean fruit fly Anastrepha suspensa (Loew) (Diptera: Tephritidae) population through augmented releases of the parasitoid Diachasmimorpha longicaudata (Ashmead) (Hymenoptera: Braconidae). Biological Control 6: 177-185.
Sivinski, J.M.; Aluja, M.; Lopez, M. 1997. Spatial and temporal distributions of parasitoids of mexican Anastrepha species (Diptera:Tephritidae) within the canopies of fruit trees. Annals of the Entomological Society of America 90: 604-618.

Sivinski, J.M.; Aluja, M.; Holler, T.; Eintan, A. 1998. Phenological comparison of two braconid parasitoids of the Caribbean fruit fly (Diptera: Tephritidae). Environmental Entomology 27: 360365.

Turchin, P. 1989. Beyond simple diffusion: models of not-so-simple movement in animals and cells. Comments in Theoretical Biology 1: 65-83.

van Alphen, J.J.M.; Bernstein, C. 2008. Information acquisition, information processing, and patch time allocation in insect parasitoids. p. 172-192. In: Wajnberg, E.; Bernstein, C.; van Alphen, J.J.M. eds. Behavioral ecology of insect parasitoids: from theoretical approaches to field applications. Blackwell Publishing, Oxford.

Zachrisson, B.; Parra, J.R.P. 1998. Dispersion capacity of Trichogramma pretiosum Riley, 1879 for the control of Anticarsia gemmatalis Hübner, 1818 in soybean. Scientia Agricola 55: 133137. 